\title{
Screening for $22 q 11$ deletion syndrome among patients with congenital heart defects
}

Triagem para a síndrome de deleção 22q11 entre pacientes com cardiopatia congênita

Rafael Fabiano Machado Rosa', Rosana Cardoso Manique Rosa", Patrícia Trevisan", Carla Graziadio"', Marileila Varella-Garcia"v, Giorgio Adriano Paskulinv, Paulo Ricardo Gazzola Zen ${ }^{\text {vi }}$

Universidade Federal de Ciências da Saúde de Porto Alegre (UFCSPA) and Complexo Hospitalar Santa Casa de Porto Alegre (CHSCPA), Porto Alegre, Rio Grande do Sul, Brazil

PhD. Professor of Postgraduate Program on Pathology, Universidade Federal de Ciências da Saúde de Porto Alegre (UFCSPA), and Clinical Geneticist, Universidade Federal de Ciências da Saúde de Porto Alegre (UFCSPA), Complexo Hospitalar Santa Casa de Porto Alegre (CHSCPA) and Hospital Materno Infantil Presidente Vargas (HMIPV), Porto Alegre, Rio Grande do Sul, Brazil. "MD. Postgraduate Student, Postgraduate Program on Pathology, Universidade Federal de Ciências da Saúde de Porto Alegre (UFCSPA), Porto Alegre, Rio Grande do Sul, Brazil. "'MD. Postgraduate Student, Postgraduate Program on Pathology and Assistant Professor of Clinical Genetics, Universidade Federal de Ciências da Saúde de Porto Alegre (UFCSPA); and Clinical Geneticist, Universidade Federal de Ciências da Saúde de Porto Alegre (UFCSPA) and Complexo Hospitalar Santa Casa de Porto Alegre (CHSCPA), Porto Alegre, Rio Grande do Sul, Brazil. "vphD. Professor of Medical Oncology and Director of the Cancer Center Cytogenetics Core, University of Colorado Denver (UCD), Aurora, Colorado, United States.

vphD. Associate Professor of Clinical Genetics and Coordinator of the Postgraduate Program on Pathology, Universidade Federal de Ciências da Saúde de Porto Alegre (UFCSPA); and Clinical Geneticist, Universidade Federal de Ciências da Saúde de Porto Alegre (UFCSPA) and Complexo Hospitalar Santa Casa de Porto Alegre (CHSCPA), Porto Alegre, Rio Grande do Sul, Brazil.

uphD. Adjunct Professor of Clinical Genetics and Professor of the Graduate Program in Pathology, Universidade Federal de Ciências da Saúde de Porto Alegre (UFCSPA); and Clinical Geneticist, Universidade Federal de Ciências da Saúde de Porto Alegre (UFCSPA) and Complexo Hospitalar Santa Casa de Porto Alegre (CHSCPA), Porto Alegre, Rio Grande do Sul, Brazil.
The 22q11 deletion syndrome (22q11DS), or velocardiofacial/DiGeorge syndrome, is considered to be the second most known genetic cause of congenital heart disease (CHD). ${ }^{1}$ Our aim was to evaluate the effectiveness of different screening methods for 22q11DS in patients with CHD. Our study evaluated a consecutive sample of patients with CHD hospitalized for the first time in a pediatric and cardiac intensive care unit of a referral hospital in southern Brazil. All of them underwent the examination through fluorescent in situ hybridization for 22q11DS. These patients were part of the study by Rosa et al. ${ }^{2}$ CHDs were classified by a cardiologist as conotruncal or non-conotruncal. We excluded patients with other chromosomal abnormalities. Three different approaches composed the screening:

(1) Testing suggested by Tobias et $\mathrm{al}^{3}{ }^{3}$ The clinical findings are divided into three categories:

A) conotruncal CHD;

B) abnormalities common in 22q11DS, such as hypocalcemia and non-conotruncal CHD; and

C) abnormalities less common in 22q11DS, such as short stature and hypotonia. Patients that have an alteration in group A, two findings in group $\mathrm{B}$, or one finding in group $\mathrm{B}$ plus one in group $\mathrm{C}$ are tested;

(2) Testing suggested by the American Heart Association (AHA) Congenital Cardiac Defects Committee, ${ }^{4}$ which consists of testing all newborns/infants with interrupted aortic arch (IAA), truncus arteriosus (TA), tetralogy of Fallot (TOF), ventricular septal defect (VSD) (perimembranous conoseptal hypoplasia or malalignment) with aortic arch anomaly (AAA), AAA alone and discontinuous branch pulmonary arteries. The screening also includes any newborn/infant/child with CHD associated with another feature of 22q11DS (such as hypocalcemia, facial dysmorphia and palate abnormality); newborns/infants with VSD, and any child/ adolescent/adult with TOF, TA, IAA, VSD or AAA who has one other feature of 22q11DS;

(3) Testing performed at some centers, ${ }^{5}$ where only patients with conotruncal heart defects are tested.

For all these approaches, we calculated the sensitivity, specificity, positive predictive value (PPV), negative predictive value (NPV) and receiver operating characteristic (ROC) curves. The significance level used was $5 \%$ ( $\mathrm{P} \leq 0.05)$. The total sample consisted of 170 patients (93 males), with ages ranging from 1 to 4934 days (mean of 847.7 days, standard deviation of 1225.1). 22q11DS was identified in four patients (2.4\%): two newborns with TOF, one newborn with VSD associated with AAA, and one adolescent with atrial septal defect. One hundred and eleven patients (65\%) met screening criterion 1, with sensitivity $100 \%$, specificity $36 \%$, PPV $3.6 \%$ and NPV $100 \%$. Criterion 2 was met by 76 (44.7\%) patients, with sensitivity $75 \%$, specificity $56 \%$, PPV 3.9\% and NPV 98.9\%. Forty-five patients (26.5\%) had conotruncal heart defects and fulfilled criterion 3 , with sensitivity 50\%, specificity 74\%, PPV $4.4 \%$ and NPV $98.4 \%$. The ROC curves are shown in Figure 1. All the areas under the ROC curves were less than 0.5 [criterion 1: $0.247(\mathrm{P}=0.083)$; criterion 2: $0.295(\mathrm{P}=0.161)$; and criterion 3: $0.374(\mathrm{P}=0.388)]$. 


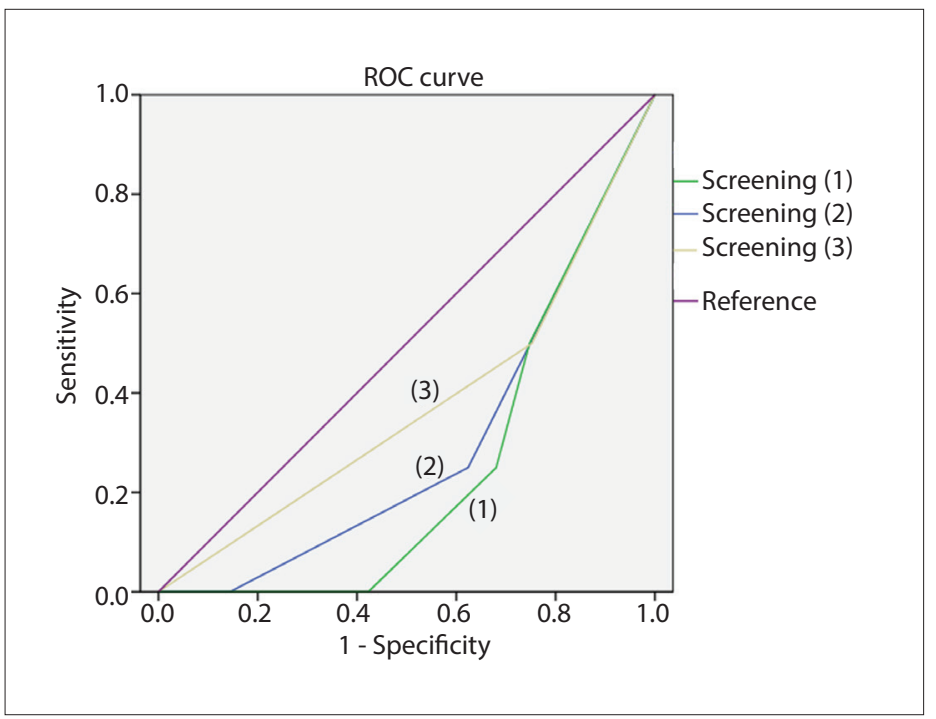

Figure 1. Receiver operating characteristic $(\mathrm{ROC})$ curves presented by the different screening criteria.

Method 1 showed the highest sensitivity (100\%). On the other hand, method 3 identified only half of the cases. However, it is noteworthy that the PPV was very low in all the approaches, i.e. many patients needed to be screened in order to diagnose the individuals with 22q11DS, and in some circumstances not all of them were diagnosed. The analysis on the ROC curves also showed that none of the criteria used presented satisfactory performance, since all of them presented areas under the ROC curve of less than 0.5 . Thus, new approaches are still needed, especially with the aim of reducing the costs involved in screening. It is possible that new and cheaper technologies such as multiplex ligation-dependent probe amplification may become applicable as screening methods.

\section{REFERENCES}

1. Rosa RFM, Zen PRG, Graziadio C, Paskulin GA. Síndrome de deleção 22q11.2 e cardiopatias congênitas [22q11.2 deletion syndrome and congenital heart defects]. Rev Paul Pediatr. 2011;29(2):251-60.

2. Rosa RF, Pilla $C B$, Pereira $V L$, et al. 22q11.2 deletion syndrome in patients admitted to a cardiac pediatric intensive care unit in Brazil. Am J Med Genet A. 2008;146A(13):1655-61.

3. Tobias ES, Morrison N, Whiteford ML, Tolmie JL. Towards earlier diagnosis of 22q11 deletions. Arch Dis Child. 1999;81 (6):513-4.

4. Pierpont ME, Basson CT, Benson DW Jr, et al. Genetic basis for congenital heart defects: current knowledge: a scientific statement from the American Heart Association Congenital Cardiac Defects Committee, Council on Cardiovascular Disease in the Young: endorsed by the American Academy of Pediatrics. Circulation. 2007;115(23):3015-38
5. Butts SC, Tatum SA 3rd, Mortelliti AJ, Shprintzen RJ. Velo-cardio-facial syndrome: the pediatric otolaryngologist's perspective. Curr Opin Otolaryngol Head Neck Surg. 2005;13(6):371-5.

Sources of funding: None

Conflict of interest: None

Date of first submission: January 11, 2013

Last received: July 15, 2013

Accepted: August 30, 2013

\section{Address for correspondence:}

Rafael Fabiano Machado Rosa

Genética Clínica

Universidade Federal de Ciências da Saúde de Porto Alegre (UFCSPA)

Rua Sarmento Leite, 245/403

Centro - Porto Alegre (RS) - Brasil

CEP 90050-170

Tel. (+55 51) 3303-8771

Fax. (+55 51) 3303-8810

E-mail: paulozen@ufcspa.edu.br

E-mail:rfmr@terra.com.br 